\title{
Immunogenetics of Type 1 Diabetes
}

\author{
Mimi S. Kim Constantin Polychronakos \\ Division of Pediatric Endocrinology, McGill University Health Center, Montreal, Canada
}

\section{Key Words}

Diabetes mellitus, type $1 \cdot$ Human leukocyte

antigens - Protein tyrosine phosphatase - Cytotoxic

T-lymphocyte-associated antigen 4 - Minisatellite repeats, insulin

\begin{abstract}
The T-cell mediated autoimmune process that destroys pancreatic $\beta$ cells in type 1 diabetes (T1D) is a complex phenotype influenced by multiple genetic and environmental factors. Human leukocyte antigen (HLA) accounts for about half of the genetic susceptibility, through a large variety of protective and predisposing haplotypes. Other important loci associated with T1D, with much smaller effects than HLA, include the insulin variable number of tandem repeats, PTPN22, and CTLA-4. Detecting the association and confirming it beyond doubt is only the first step. Identifying the functional variant from among a block of polymorphisms in tight linkage disequilibrium and determining its biological consequences can be an even more challenging task. It is hoped that the identification of additional loci and functional analysis of known ones, no matter how small each individual effect is, will provide: (1) pathophysiological insights necessary for the development of preventive interventions; (2) risk prediction to identify individuals that can benefit from them, and (3) potentially, identification of distinct subgenotypes, with different immune dysregulation pathways leading to the common disease phenotype that may respond to different preventive interventions.
\end{abstract}

Copyright $(2005$ S. Karger AG, Basel

\section{KARGER}

Fax +4161306 1234 E-Mail karger@karger.ch www.karger.com

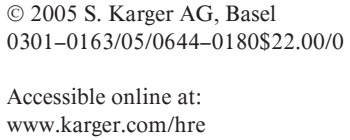

\section{Introduction}

Type 1 diabetes (T1D) is a complex disease due to autoimmune destruction of the pancreatic $\beta$ cells. This is a result of multiple genetic and environmental influences. In population-based twin studies, the concordance rate of monozygotic twins is $40-50 \%$ [1]. In contrast, in dizygotic twins the concordance rate is similar to the frequency in siblings $(5-10 \%)$ which is still more than 10 fold the prevalence $(0.2-0.4 \%)$ found in the general population [2]. This suggests that genetic susceptibility accounts for somewhat less than half of the etiology of T1D.

\section{T1D Susceptibility as a Genetic Trait}

The abrupt fall in risk with the degree of relatedness also suggests that the disease depends on a combination of alleles at multiple gene loci, with the effect of each locus generally being small. Most of the genes involved in T1D susceptibility, however, remain unknown. To date, all known genetic associations have been detected on the basis of the candidate gene approach. This involves some prior knowledge of the pathophysiology of the process, and the evaluation of polymorphisms (in genes encoding key proteins) for differences in allele frequencies in affected individuals versus controls. The alternative is the positional approach, in which the gene is identified without prior functional knowledge, on the basis of its location in the genome. This location is identified on the basis of coinheritance of the corresponding chromosomal seg-
Constantin Polychronakos

Division of Pediatric Endocrinology, McGill University Health Center

2300 Tupper, Montreal, QC, H3H 1 P3 (Canada)

Tel. +1 514412 4315, Fax +1 5144124264

E-Mail constantin.polychronakos@mcgill.ca 
ment with the disease phenotype: pairs of diabetic siblings are genotyped at arbitrary polymorphic markers, equally spaced throughout the genome, to identify regions shared by them at a frequency higher than the expected $50 \%$. This positional approach, so successful with monogenic or Mendelian disorders, has resulted in the naming of eighteen loci (IDDM1-IDDM18) [3], of which almost all have turned out to be statistical artifacts due to underestimates of the sample size required for meaningful statistical power [4].

\section{Environmental Influences}

The dramatic increase of T1D over the last two generations in Finland [5], and more than doubling in some countries, clearly points to the presence of environmental factors, but little is known about their precise nature. Viruses and nutritional factors (mostly cow's milk protein) have been incriminated [6-8], but definitive proof in the form of multiple confirmations is lacking for any of them. Once these factors are identified, their interaction with the other components of genetic susceptibility will lead to a full understanding of disease etiology.

\section{Immunology of T1D}

It appears that the cellular autoimmunity in T1D responsible for the destruction of pancreatic $\beta$ cells is mediated by $T$ cells. $B$ cells produce autoantibodies to $\beta$-cell antigens, and in turn present these self-antigens (glutamic acid decarboxylase 65 , insulin, tyrosine phosphatase) to $\mathrm{T}$ cells. However, a case report of a patient with Xlinked agammaglobulinemia who developed T1D suggests that B cells and autoantibodies are not strictly required in this autoimmune process [9]. Most T1D patients can be subclassified as autoimmune (type 1a). On the other hand, the etiology is unknown in a small percentage that lacks any evidence of autoimmunity (type 1b). The main difference between these T1D types is that type 1a patients have islet cell antibodies that serve as markers of disease, primarily in the first year of diagnosis, without playing a role in $\beta$ cell destruction. Known autoantigens include insulin, glutamic acid decarboxylase, and antibodies against the islet cell antigen 512 phosphatase (IA-2), of which only insulin is $\beta$ cell specific. Insulin autoantibodies occur more in DR4 haplotype patients and are useful if measured prior to administering exogenous insulin. Glutamic acid decarboxylase antibodies persist the longest following diagnosis and are useful in confirming autoimmune etiology in long-standing cases. The presence of more than one type of antibody is highly predictive of disease, years before clinical manifestations occur [10].

It is unclear what leads to this dysregulation of autoimmunity in T1D. It must result from some imbalance between effector $\mathrm{T}$ cells and regulatory $\mathrm{T}$ cells. Most $\mathrm{T}$ cells have effector function, and are thus programmed to mount the host-defense response to infection. On the other hand, regulatory $\mathrm{T}$ cells - a recently recognized T-cell subset - are programmed to moderate the reactivity of effector $\mathrm{T}$ cells, for the purpose of protecting self.

\section{HLA Class II (IDDM1 Locus)}

The first candidate locus studied and found to be strongly associated with T1D was the human leukocyte antigen (HLA) region on chromosome 6p21.3 [11, 12]. This cluster of homologous cell-surface proteins is divided into class I (A, B, C) and class II (DP, DQ, DR). These proteins are unique in that they are more than an order of magnitude more polymorphic than any other protein in the human genome. This diversity is driven by the positive selection of new alleles that confer the advantage of heterozygosity. This increases the ability to optimally bind a broader range of epitopes and remain current with the evolution of pathogens.

The single-chain class I molecules are ubiquitously expressed and present intracellular antigen to CD8+ cells. Class II molecules are composed of A and B chains and are responsible for presenting extracellular antigen to CD4+ cells, via specialized antigen-presenting cells (fig. 1).

Genetically, the class II region has been found to contribute strongly to T1D susceptibility, attributable mostly to the DR and DQ genes. However, assigning relative importance to each gene, and detecting smaller effects from other genes in the region, is hampered by very strong linkage disequilibrium (LD). LD refers to the strong correlation between alleles at neighboring single nucleotide polymorphisms (SNPs) that are inherited as a block [13]. The association is, therefore, mapped to whole clusters of adjacent alleles (i.e., haplotypes) which encompass more than one gene, rather than to individual alleles.

Alleles are designated with a number that follows an asterisk. Most T1D-relevant polymorphisms are amino acid changes in exon 2 of the A chain of DR and both A 
Fig. 1. HLA region on chromosome $6 \mathrm{p} 21.3$. The class I region is comprised of $\mathrm{A}, \mathrm{B}$, and $\mathrm{C}$ genes and the class II region of DP, DQ, and DR. Each class II molecule is encoded by adjacent genes for an a and b chain. Most of the genetic contribution is made by class II. Most type 1 diabetes-relevant polymorphisms are amino acid changes in the a chain of DR and both a and $b$ chains of DQ. Functionally, class I molecules present intracellular antigen to CD8+ T cells, class II molecules present extracellular antigen to CD4+ cells.

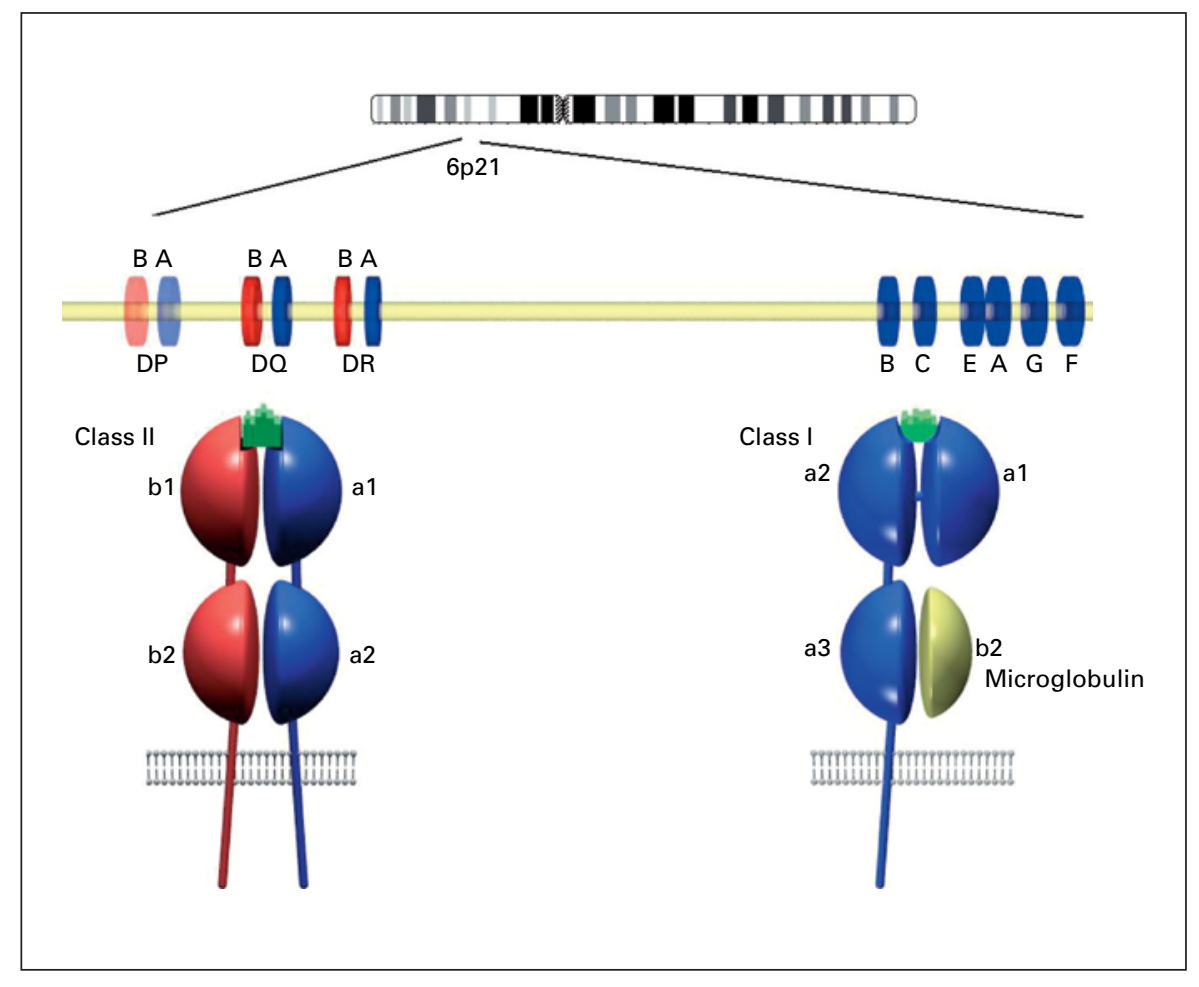

and $\mathrm{B}$ chains of DQ. Thus, the most common T1D-predisposing haplotypes in Caucasians are DRB $1 * 0301$ DQA1*0501-DQB1*0201 and DRB1*0401-DQA1* 0301-DQB1*0302 [14]. These are abbreviated by their serological designations, respectively, as DR3-DQ2 and DR4-DQ8. Interestingly, heterozygosity for DQ2/DQ8 (which, because of LD almost always implies DR3/DR4 heterozygosity) confers the highest T1D risk in Caucasians. The risk is higher than homozygosity for either haplotype, indicating qualitative rather than merely quantitative interactions between alleles. This genotype is found in $3 \%$ of the general population, but in $30 \%$ of T1D patients, conferring a 15 -fold relative risk and an earlier onset of disease. Most of the remaining Caucasians with T1D have at least one of these two haplotypes.

Conversely, the HLA-DQ6 haplotype, DRB1*1501DQA1*0102-DQB1*0602, has a protective association with T1D. It is found in $<1 \%$ diabetic children and $20 \%$ of the general population $[14,15]$. If it is in combination with a predisposing haplotype, the individual remains at low risk [16].

At a molecular level, at-risk alleles differ structurally from protective alleles. Most characteristic is the absence of an aspartic acid molecule at position 57 of the $\beta$ chain of the DQ molecule. This reverses the electric charge of the peptide-binding groove of the HLA-DQ8 molecule, thereby possibly altering the binding of insulin epitopes [17].

The role of HLA in T1D was further studied in animal models. The equivalent to HLA in mice is the major histocompatibility complex (MHC). Work on autoimmuneprone nonobese diabetic (NOD) mice expressing a diabetogenic human HLA class II gene in the presence of a mouse diabetes-resistant MHC class II genotype failed to develop diabetes [18-21]. In fact, in NOD mice with a transgene expressing higher levels of its own diabetogenic MHC class II molecules, there was a decrease in diabetes frequency [22]. This indicates that MHC alleles predispose to diabetes through loss of desirable function, rather than gain of undesirable function. It is therefore speculated that weak binding of some crucial T1D-related autoepitope(s) by predisposing class II alleles fails to generate sufficient tolerance, either thymic or peripheral. This could result in the targeting of the autoepitope in the periphery, under conditions of aberrant immune function, as created by other genetic loci or environmental inputs [23]. 
Table 1. Transmission disequilibrium tests of single nucleotide polymorphisms (SNPs) in the INS, PTPN22, and CTLA4 genes

\begin{tabular}{lllll}
\hline Gene & SNP & $\begin{array}{l}\text { Minor allele } \\
\text { (frequency) }\end{array}$ & p value & $\begin{array}{l}\text { Odds ratio } \\
(95 \% \mathrm{CI})\end{array}$ \\
\hline INS & INS-VNTR & $\mathrm{T}(0.182)$ & $2.59 \times 10^{-10}$ & $1.96(1.60,2.41)$ \\
CTLA4 & 3' flanking SNP & $\mathrm{A}(0.427)$ & $4.11 \times 10^{-2}$ & $1.16(1.01,1.33)$ \\
CTLA4 & Signal peptide Thr17Ala & $\mathrm{G}(0.393)$ & $2.43 \times 10^{-2}$ & $1.18(1.02,1.36)$ \\
CTLA4 & Promoter SNP & $\mathrm{T}(0.090)$ & $3.42 \times 10^{-2}$ & $1.30(1.03,1.66)$ \\
PTPN22 & aa substitution R620W & $\mathrm{A}(0.145)$ & $9.61 \times 10^{-7}$ & $1.86(1.45,2.39)$ \\
\hline
\end{tabular}

INS and CTLA4 data are unpublished data from genetic association studies performed in our lab. PTPN22 data is adapted from [49]. All data are derived from a Caucasian population. All SNPs have two alleles; the minor (rare) allele frequency represents how often this SNP is seen in the population. The OR (odd ratio) can be used to represent the relative risk of an SNP in the human population, with a value of $>1$ indicating risk. Based on the table by Huiqi Qu.

\section{Non-HLA Loci}

The HLA haplotypes of highest risk are found commonly in the general population, but only a fraction of these carriers develop T1D. This low penetrance indicates that HLA cannot account for all of the genetic susceptibility to T1D. One quarter of all siblings of T1D patients share no HLA haplotype with their affected sibling, yet these individuals have a T1D risk 7-fold higher than the general population. On this basis it was calculated that HLA accounts for about $40-50 \%$ of the genetic risk [2]. Linkage studies have clearly shown that there is no other T1D locus of an amplitude of effect approaching this (table 1). Discovering the numerous other loci responsible for the rest of the genetic susceptibility, no matter how small the individual effects may be, is important in understanding the disease.

\section{INS-VNTR (IDDM2)}

A polymorphism in the $5^{\prime}$ flanking region of the insulin gene (INS) on chromosome $11 \mathrm{p} 15.5$ has been known for two decades to be associated with T1D [24]. It consists of a variable number of tandem repeats (VNTR, also referred to as a minisatellite) polymorphism, located 365 bp upstream of INS, outside coding sequences (fig. 2); there is tandem repetition of a 14- to 15-bp oligonucleotide that is related to a consensus sequenceACAGGGGTGTGGGG [25-28]. The number of repeats shows a bimodal distribution with alleles clustering either at 30-60 repeats (class I) or 120-170 repeats (class III), with intermediate sizes (class II) being very rare. Homozygosity for the class I alleles confers a relative risk of 2-3 compared with the presence of at least one class III allele. Conversely stated, the less frequent class III alleles have a dominant protective effect.

The INS-VNTR polymorphism does not affect the insulin peptide sequence. Therefore, and given its location upstream of the INS promoter, its biological effects are most likely mediated through allelic differences in INS transcription levels. Indeed, there is a small, but statistically significant, increase in insulin mRNA expression by class I, in comparison to class III alleles, on insulin expression in both fetal and adult pancreas [29, 30]. Such marginal loss of function, however, is not a satisfactory explanation for a dominant effect. In addition to the pancreas, small amounts of insulin (as well as many other tissuerestricted proteins) are known to be expressed in the thymus epithelium [31], an expression likely related to development of central tolerance [31-33]. In fact, it appears that it is in the thymus that the INS-VNTR exerts biologically important effects. The predisposing class I VNTR alleles are associated with 2- to 3-fold lower insulin levels in the thymus. If insulin is expressed in the thymus for the development of self-tolerance, then lower levels of insulin could hamper the process of negative selection, whereby there would be less binding of $\mathrm{T}$ cells to insulin self-antigen, and less deletion of insulin-specific autoreactive $\mathrm{T}$ cells $[34,35]$. Mice that were engineered to have a graded thymic insulin deficiency, while pancreatic insulin remained unaltered, exhibited a detectable peripheral T-cell response to proinsulin even against a nondiabetogenic background $[36,37]$. Bred against the NOD background, these mice show marked acceleration of insulitis and diabetes [38]. Importantly, enhanced re- 
Fig. 2. Insulin VNTR minisatellite repeats. The INS-VNTR is located 365 bp upstream from the insulin gene (INS) promoter. It is also $5 \mathrm{~kb}$ upstream from a second potential target for regulation, insulin-like growth factor II $(I G F 2)$ and $10 \mathrm{~kb}$ downstream of the tyrosine hydroxylase gene $(\mathrm{TH})$. Class I and class III differ by the number of tandem repeats of the VNTR consensus sequence. Class I predispose to and class III protect from type 1 diabetes. Adapted from [47].

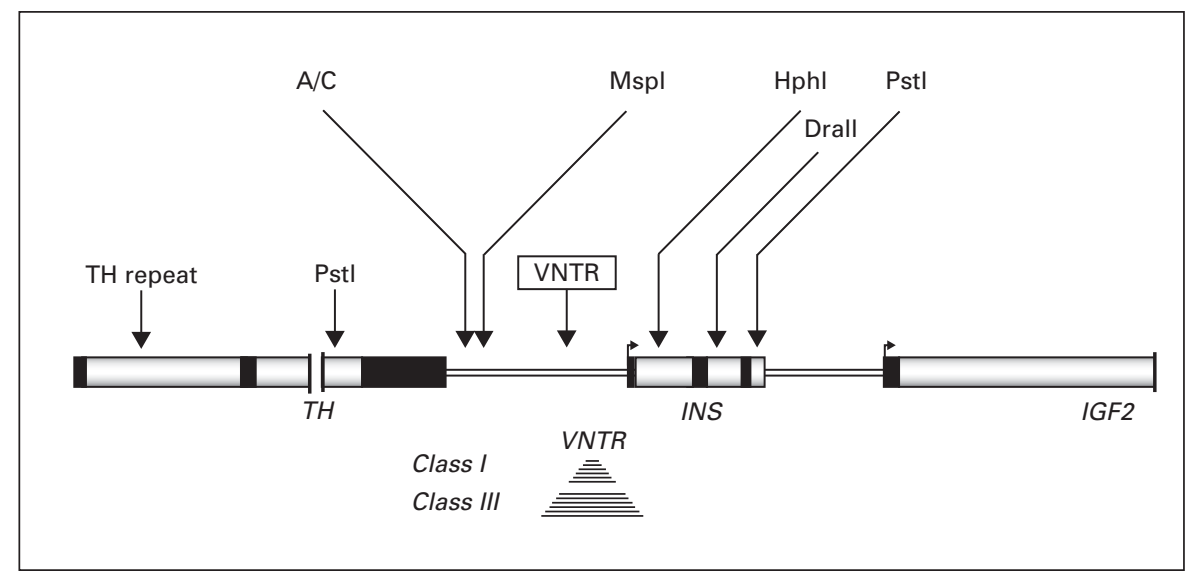

activity in these mice was confined to insulin and did not affect autoimmunity against other autoantigens.

An interesting twist, and additional support for the importance of thymic expression of insulin, involves two rare class III VNTR alleles that were found to silence thymic insulin transcripts completely, instead of enhancing them. In genetic studies these alleles were found to predispose to, rather than protect from, T1D [39].

Another potential target for allelic regulation by the VNTR is $I G F 2$, which is located $5 \mathrm{~kb}$ downstream, and encodes the insulin-like growth factor II. However, this gene was studied and no difference was noted in $I G F 2$ mRNA expression between the two VNTR class alleles in human pancreatic or thymic tissue [40, 41].

\section{CTLA-4}

The cytotoxic T-lymphocyte-associated antigen 4 (CTLA-4) gene was studied as a good candidate gene for T1D because it encodes a T-cell receptor (TCR) that mediates apoptosis in activated T cells. The TCR is a transmembrane glycoprotein expressed within 2-3 days following T-cell activation.

CTLA-4 maps to $2 \mathrm{q} 33$ within one of the linkage loci (IDDM12). Its association with T1D [42] was subsequently confirmed by multiple groups [43-46] and mapped to an LD block in the D2S72-CTLA-4-D2S116 region [43, 44]. A large study found association of the same region in Graves' disease, and autoimmune hypothyroidism, in addition to T1D [44]. This chromosome interval also contains $C D 28$ and inducible T-cell co-stimulator (ICOS), two other candidate genes important in immune function. However, these genes lie outside the associated LD block (fig. 3). In Graves' disease, an A6230G SNP in the $3^{\prime}$ flanking region of CTLA-4 exhib- its the strongest association. This SNP was also found to be important in T1D but could not explain all of the observed association, and effects from the $5^{\prime}$ end could not be ruled out [44]. That region includes an A49G nonsynonymous SNP (Thr17Ala) in the signal peptide and several promoter SNPs.

The mechanism by which the $\mathrm{A} 6230 \mathrm{G}$ polymorphism affects the disease is unknown. Allelic effects on mRNA levels, restricted to a soluble isoform of CTLA-4 whose transmembrane domain is spliced out, has been proposed [44]. This mechanism could involve alternative splicing, polyadenylation, or RNA stability only of the soluble, but not of the full-length, isoforms [47]. However, other groups have failed to reproduce this finding [48]. As there are no transcriptional effects of $\mathrm{A} 6230 \mathrm{G}$ on the downstream ICOS gene either [48], the mechanism of the effect of this SNP remains unknown.

The independent contribution from the $5^{\prime}$ end of the gene may be related to the signal peptide Thr17Ala substitution, shown to affect glycosylation and surface targeting of CTLA-4 [45], or from a promoter polymorphism in the $5^{\prime}$-flanking region with demonstrated transcriptional effects on the expression of CTLA-4 [46].

Overall, however, compared to HLA or even the insulin locus, the contribution of the CTLA-4 locus to the susceptibility to $\mathrm{T} 1 \mathrm{D}$ is minor $(\mathrm{RR} \simeq 1.2)$.

\section{PTPN22}

A recent association of T1D with an SNP in the lymphoid protein tyrosine phosphatase, nonreceptor type 22 gene was found in a case-control study [49] and confirmed by multiple groups [50-53]. PTPN22 maps to chromo- 


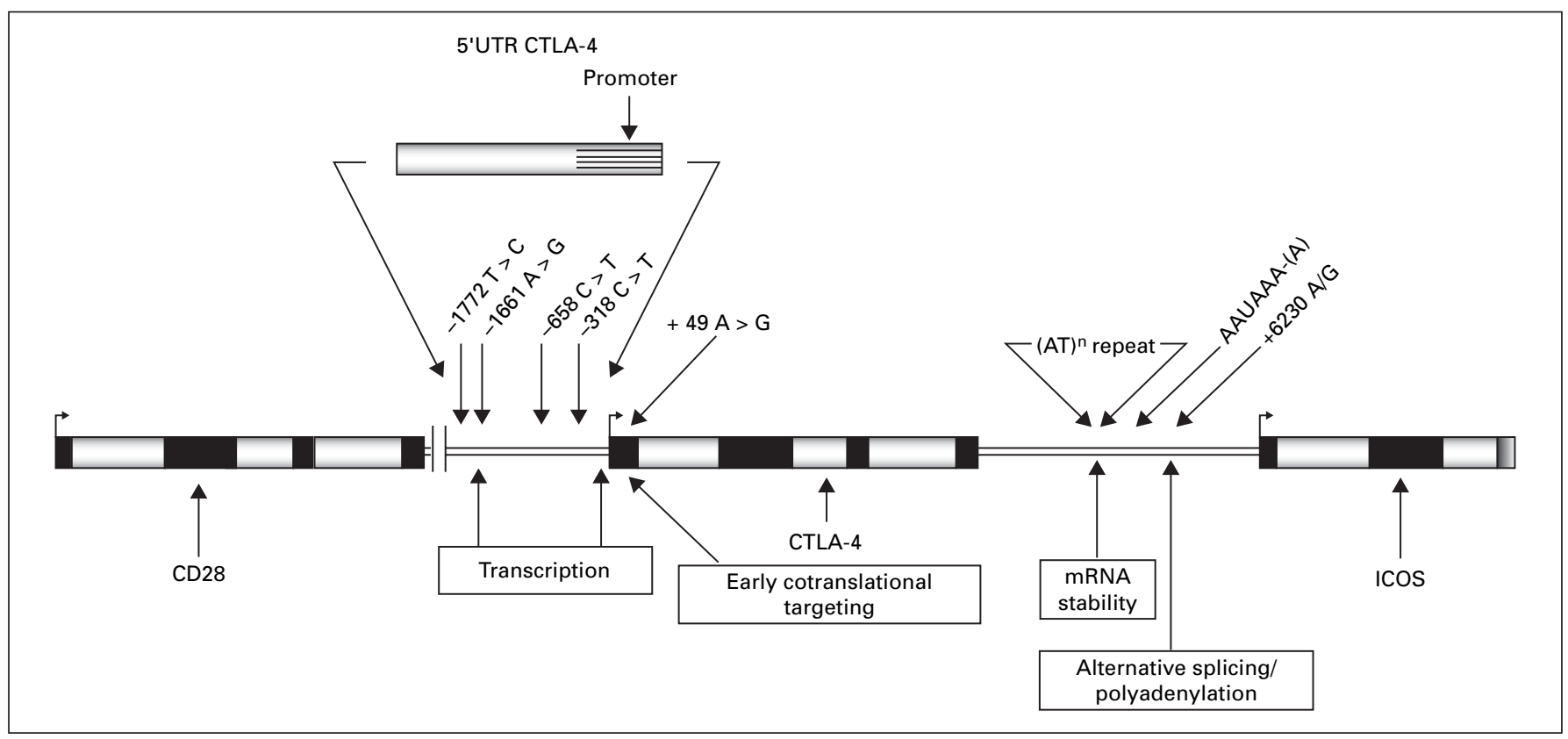

Fig. 3. $C T L A-4$ on chromosome 2q33. $C T L A-4$ and its flanking $5^{\prime}$ and $3^{\prime}$ regions lie within a type 1 diabetes (T1D)-associated LD block. CD28 and ICOS, two other candidate genes important in immune function, lie outside the haplotype block. The A6230G single nucleotide polymorphism (SNP) in the 3' flanking region of CTLA4 exhibits a strong association with Graves' disease and T1D, through an unknown mechanism. Effects from the $5^{\prime}$ end of the region also cannot be ruled out, with either a promoter polymorphism or an amino acid substitution in the signal peptide. Various SNPs and their potential mechanism of action are noted. Adapted from [47].

some 1p13.3-p13.1 and encodes Lyp - a nonreceptor tyrosine phosphatase specific to lymphocytes - which suppresses $\mathrm{T}$-cell activation by dephosphorylating three kinases important to T-cell signaling [54]. It also downregulates $\mathrm{T}$-cell activation by interacting with a suppressor of kinases known as C-terminal Src tyrosine kinase (Csk) [55]. The SNP results in a R620W amino acid substitution that abolishes the binding of Lyp to its C-terminal Src tyrosine kinase partner.

Functionally, $P T P N 22$ is a compelling candidate gene, as protein tyrosine phosphatases play important roles in TCR signaling. Targeted disruption of PEST domain-enriched tyrosine phosphatase, the mouse analog of PTPN22, results in increased numbers of memory $T$ cells that could accentuate any autoimmune phenomena [56]. In another mouse model, disruption of binding to C-terminal Src tyrosine kinase with an induced mutation mimicking R620W resulted in loss of PEST domain-enriched tyrosine phosphatase inhibition of TCR signaling [57].

However, it must be noted that this polymorphism maps to a solid 293-kb LD block that contains at least 6 other known genes and 625 known SNPs. Therefore, there is still the possibility that there is another potentially functional SNP accounting for the observed LD, and functional studies are needed to distinguish between the SNPs and confirm that R620W is indeed responsible for the biological effect. The concept of how LD helps some aspects of the search for genetic susceptibility and hampers others is explained in figure 4 and the accompanying text box.

\section{Conclusion/Future Research}

Besides the pure scientific interest, what is the relevance of elucidating the genetics of a complex disease like T1D to the practice of medicine? Risk prediction and gene therapy are often mentioned. However, risk prediction without prevention is of little benefit to the patient, and may do more harm than good. Gene therapy to redress the rather subtle functional effects of a multitude of genetic variants does not appear to be a plausible scenario either. 


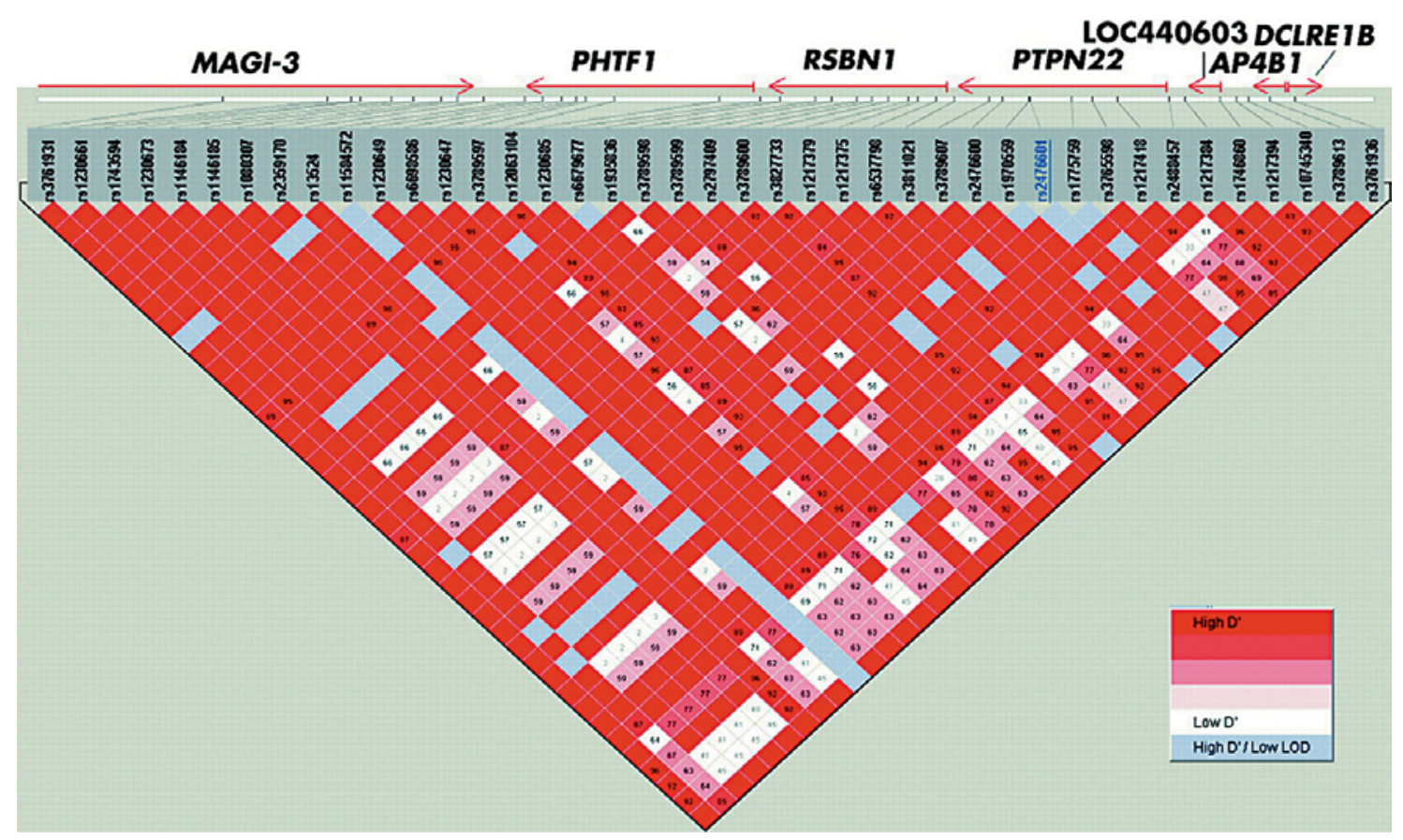

Fig. 4. The PTPN22 linkage disequilibrium (LD) block, found to be associated with T1D, is illustrated. The solid, $300-\mathrm{kb}$ block contains 5 other genes in addition to PTPN22 and over 600 known single nucleotide polymorphisms (SNPs). Forty of the SNPs genotyped in the HapMap project, plus R620W (highlighted in blue), are shown under the cartoon of the gene positions at the top of the diagram. The rest of the graph shows the pair-wise LD measures for any pair of two SNPs in this diagram, at the position at which the row and column of the half-square that correspond to the two SNPs intersect. Red without a number corresponds to a d' value of 1 . $\mathrm{D}^{\prime}$ values may range from zero (no LD) to 1 (no recombination between the two loci). Reproduced with permission from the British Medical Journal Publishing Group [50].

\section{Linkage Disequilibrium: A Complex Role}

Linkage disequilibrium (LD) enormously facilitates the search for genetic associations with complex diseases like diabetes because genotyping a small fraction of all polymorphisms can give most of the information that would have been obtained by genotyping all. However, once the association has been detected, attributing the association to the specific functional variant responsible for the biological effect may be complicated by the presence of LD. A good example is the association of T1D with PTPN22, as illustrated in figure 4. The association could have been discovered by genotyping any of a number of the SNPs over the 300-kb haplotype block. R620W is one SNP that is convincing on functional grounds. However, the association could still be due to an unknown functional effect of any of a number of the SNPs in figure 4, plus one or more of the hundreds of SNPs in this interval that have not been genotyped.

The main motive for understanding the genetics of T1D is for generating insights towards a complete understanding of disease pathophysiology, necessary for the development of more conventional immune interventions to prevent $\beta$-cell destruction.
Ultimately, however, one might speculate that the most important benefit from knowledge of genetic susceptibility to complex traits might come from the ability to distinguish different predisposing genotypes among patients carrying the same diagnostic label because of a 
common end-point phenotype (HLA-dependent autoimmune $\beta$-cell destruction, as in the case of T1D). As we have previously argued, this common end-point may be the result of quite different loss-of-tolerance pathways in different individuals $[58,59]$.

The study of autoimmune diabetes in rodent models supports a compelling argument in favor of this speculation. The NOD mouse and the BioBreeding rat are spontaneous, autoimmune, MHC-dependent diabetes models involving insulitis, autoantibodies, and T-cell responses to the same autoantigens as human T1D. These two inbred strains are genetically the equivalent of 2 human patients. Each has a quite distinct immune dysregulation phenotype, neither of which has been reproducibly found in human T1D patients taken as a whole [58]. It may be that a small percentage of human patients get T1D for the same reason as the NOD mouse, another small percentage have the same dysregulation as the BioBreeding rat, and the remaining get their $\beta$ cells destroyed as a result of different disruptions.

We believe that it is reasonable to envision a future scenario in which genotyping individuals in the general population for a panel of T1D-related genetic polymorphisms will not only identify the small percentage who are at high risk and can benefit from preventive interventions, but also suggest a choice, from a range of alternatives, of the intervention most likely to be effective in a particular case. This would allow for individualized medicine in T1D.

\section{References}

1 Kyvik KO, Green A, Beck-Nielsen H: Concordance rates of insulin dependent diabetes mellitus: a population based study of young Danish twins. Br Med J 1995;311:913-917.

$\checkmark 2$ Risch N: Assessing the role of HLA-linked and unlinked determinants of disease. Am J Hum Genet 1987;40:1-14

3 Davies JL, Kawaguchi Y, Bennett ST, Copeman JB, Cordell HJ, Pritchard LE, Reed PW, Gough SCL, Jenkins SC, Palmer SM, Balfour KM, Rowe B, Farrall M, Barnett AH, Bain SC, Todd JA: A genome-wide search for human type 1 diabetes susceptibility genes. Nature 1994;371:130-136.

4 Cox NJ, Wapelhorst B, Morrison VA, Johnson L, Pinchuk, L, Spielman RS, Todd JA, Concannon P: Seven regions of the genome show evidence of linkage to type 1 diabetes in a consensus analysis of 767 multiplex families. Am J Hum Genet 2001;69:820-830.

5 Tuomilehto J, Karvonen M, Pitkaniemi J, Virtala E, Kohtamaki K, Toivanen L, Tuomilehto-Wolf E, The Finnish Childhood Type I Diabetes Registry Group: Record-high incidence of Type I (insulin-dependent) diabetes mellitus in Finnish children. Diabetologia 1999;42: 655-660.

6 Knip M, Akerblom HK: Environmental factors in the pathogenesis of type 1 diabetes mellitus. Exp Clin Endocrinol Diabetes 1999;107: S93-S100.

7 Ellis TM, Atkinson MA: Early infant diets and insulin-dependent diabetes. Lancet 1996;347: 1464-1465.

-8 Dahlquist GG: Viruses and other perinatal exposures as initiating events for beta-cell destruction. Ann Med 1997;29:413-417.

$\checkmark 9$ Martin S, Wolf-Eichbaum D, Duinkerken G, Scherbaum WA, Kolb H, Noordzij JG, Roep BO: Development of type 1 diabetes despite severe hereditary B-cell deficiency. N Engl J M 2001;345:1036-1040.

10 Winter WE, Harris N, Schatz D: Immunological markers in the diagnosis and prediction of autoimmune Type 1a diabetes. Clin Diabetes 2002;20:183-191.

11 Nerup J, Platz P, Andersen OO, Christy M, Lyngsoe J, Poulsen JE, Ryder LP, Thomsen M, Nielsen LS, Svejgaard A: HLA antigens and diabetes mellitus. Lancet 1974;304:864-866.

12 Cudworth AG, Woodrow JC: Evidence for HLA linked genes in 'juvenile' diabetes mellitus. Br Med J 1975;3:133-135.

13 Gabriel SB, Schaffner SF, Nguyen H, Moore JM, Roy J, Blumenstiel B, Higgins J, DeFelice M, Lochner A, Faggart M, Liu-Cordero SN, Rotimi C, Adeyemo A, Cooper R, Ward R, Lander ES, Daly MJ, Altshuler D: The structure of haplotype blocks in the human genome. Science 2002;296:2225-2229.

14 Fain PR, Eisenbarth GS: Type 1 Diabetes, Autoimmunity, and the MHC; in Lowe WL Jr (ed): Genetics of Diabetes Mellitus. Norwell, MA, Kluwer Academic Publishers, 2001, pp 43-63.

15 Noble JA, Valdes AM, Cook M, Klitz W, Thomson G, Erlich HA: The role of HLA class II genes in insulin-dependent diabetes mellitus - molecular analysis of 180 Caucasian, multiplex families. Am J Hum Genet 1996; 59:1134-1148.

16 Pugliese A, Gianani R, Moromisato R, et al: 1995 HLA-DQB $1 * 0602$ is associated with dominant protection from diabetes even among islet cell antibody positive first degree relatives of patients with insulin-dependent diabetes. Diabetes 1995;44:608-613.

17 Todd JA, Bell JI, McDevitt HO: HLA-DQ beta gene contributes to susceptibility and resistance to insulin-dependent diabetes mellitus. Nature 1987;329:599-604.

18 Anderson MS, Bluestone JA: The NOD Mouse: a Model of Immune Dysregulation. Annu Rev Immunol 2005;23:447-485.

19 Nishimoto H, Kikutani H, Yamamura K, Kishimoto T: Prevention of autoimmune insulitis by expression of I-E molecules in NOD mice. Nature 1987;328:432-434.
20 Uehira M, Uno M, Kurner T, Kikutani H, Mori $\mathrm{K}$, Inomoto $\mathrm{T}$, Uede $\mathrm{T}$, Miyazaki J, Nishimoto H, Kishimoto T, et al: Development of autoimmune insulitis is prevented in E alpha d but not in A beta k NOD transgenic mice. Int Immunol 1989;1:209-213.

21 Lund T, O'Reilly I, Hutchings P, Kanagawa O, Simpson E, Gravely R, Chandler P, Dyson J, Picard JK, Edwards A, Kioussis D, Cooke A: Prevention of insulin-dependent diabetes mellitus in non-obese diabetic mice by transgenes encoding modified I-A beta-chain or normal I-E alpha-chain. Nature 1990;345:727-729.

22 Wherrett DK, Singer SM, McDevitt HO: Reduction in diabetes incidence in an I-Ag7 transgenic nonobese diabetic mouse line. Diabetes 1997;46:1970-1974.

23 Wong FS, Wen L: The study of HLA class II and autoimmune diabetes. Curr Mol Med 2003; 3:1-15.

24 Bell GI, Horita S, Karam JH: A polymorphic locus near the human insulin gene is associated with insulin-dependent diabetes mellitus. Diabetes 1984;33:176-183.

25 Lucassen AM, Julier C, Beressi JP, Boitard C, Froguel P, Lathrop M, Bell JI: Susceptibility to insulin dependent diabetes mellitus maps to a $4.1 \mathrm{~kb}$ segment of DNA spanning the insulin gene and associated VNTR. Nat Genet 1993; 4:305-310.

26 Owerbach D, Gabbay KH: Localization of a type I diabetes susceptibility locus to the variable tandem repeat region flanking the insulin gene. Diabetes 1993;42:1708-1714.

27 Bennett ST, Lucassen AM, Gough SC, Powell EE, Undlien DE, Pritchard LE, Merriman ME, Kawaguchi Y, Dronsfield MJ, Pociot F, Nerup J, Bouzekri N, Cambon-Thomsen A, Rønningen KS, Barnett AH, Bain SC, Todd JA: Susceptibility to human type 1 diabetes at IDDM2 is determined by tandem repeat variation at the insulin gene minisatellite locus. Nat Genet 1995;9:284-292. 
-28 Undelien DE, Bennett ST, Todd JA, Akselsen HE, Ikaheimo I, Reijonen H, Knip M, Thorsby E, Ronningen KS: Insulin gene region encoded susceptibility to IDDM maps upstream of the insulin gene. Diabetes 1995;44:620-625.

-29 Vafiadis P, Bennett ST, Colle E, Grabs R, Goodyer CG, Polychronakos C: Imprinted and genotype-specific expression of genes at the IDDM2 locus in pancreas and leucocytes. $\mathrm{J}$ Autoimmun 1996;9:397-403.

>30 Bennett ST, Wilson AJ, Cucca F, Nerup J, Pociot F, McKinney PA, Barnett AH, Bain SC, Todd JA: IDDM2-VNTR-encoded susceptibility to type 1 diabetes: dominant protection and parental transmission of alleles of the insulin gene-linked minisatellite locus. J Autoimmun 1996;9:415-421.

>31 Derbinski J, Schulte A, Kyewski B, Klein L: Promiscuous gene expression in medullary thymic epithelial cells mirror the peripheral self. Nat Immunol 2001;2:1032-1039.

-32 Heath WR, Allison J, Hoffmann MW, Schonrich G, Hammerling G, Arnold B, Miller JF: Autoimmune diabetes as a consequence of locally produced interleukin-2. Nature 1992; 359:547-549.

-33 Smith KM, Olson DC, Hirose R, Hanahan D: Pancreatic gene expression in rare cells of thymic medulla: evidence for functional contribution to T cell tolerance. Int Immunol 1997;9: 1355-1365.

-34 Vafiadis P, Bennett ST, Todd JA, Nadeau J, Grabs R, Goodyer CG, Wickramasinghe S, Colle E, Polychronakos C: Insulin expression in human thymus is modulated by INS VNTR alleles at the IDDM2 locus. Nat Genet 1997; 15:289-292.

- 35 Pugliese A, Zeller M, Fernandez A, Zalcberg LJ, Bartlett RJ, Ricordi C, Pietropaolo M, Eisenbarth GS, Bennett ST, Patel DD: The insulin gene is transcribed in the human thymus and transcription levels correlated with allelic variation at the INS VNTR-IDDM2 susceptibility locus for type 1 diabetes. Nat Genet 1997; 15:293-297.

>36 Chentoufi AA, Polychronakos C: Insulin expression levels in the thymus modulate insulinspecific autoreactive T-cell tolerance. The mechanism by which the IDDM2 locus may predispose to diabetes. Diabetes 2002;51: 1383-1390.

>37 Faideau B, Briand J, Lotton C, Tardivel I, Halbout P, Jami J, Elliott, JF, Krief P, Muller S, Boitard C, Carel J: Expression of preproinsulin-2 gene shapes the immune response to preproinsulin in normal mice. J Immunol 2004; 172:25-33.

-38 Thebault-Baumont K, Dubois-Laforgue D, Krief P, Briand JP, Halbout P, Vallon-Geoffroy K, Morin J, Laloux V, Lehuen A, Carel JC, Jami J, Muller S, Boitard C: Acceleration of type 1 diabetes mellitus in proinsulin 2-deficient NOD mice. J Clin Invest 2003;111:851857.
39 Vafiadis P, Ounissi-Benkalha H, Palumbo M, Grabs R, Rousseau M, Goodyer CG, Polychronakos C: Class III alleles of the variable number of tandem repeat insulin polymorphism associated with silencing of thymic insulin predispose to type 1 diabetes. J Clin Endocrinol Metab 2001;86:3705-3710.

40 Vafiadis P, Bennett ST, Todd JA, Grabs R, Polychronakos $\mathrm{C}$ : Divergence between genetic determinants of IGF2 transcription levels in leukocytes and of IDDM2-encoded susceptibility to type 1 diabetes. J Clin Endocrinol Metab 1998;83:2933-2939.

41 Vafiadis P, Grabs R, Goodyer CG, Colle E, Polychronakos C: A functional analysis of the role of IGF2 in IDDM2-encoded susceptibility to type 1 diabetes. Diabetes 1998;47:831836.

42 Nistico L, Buzzetti R, Pritchard LE, Van der Auwera B, Giovannini C, Bosi E, Larrad MT, Rios MS, Chow CC, Cockram CS, Jacobs K, Mijovic C, Bain SC, Barnett AH, Vandewalle CL, Schuit F, Gorus FK, Tosi R, Pozzilli P, Todd JA: The CTLA-4 gene region of chromosome $2 \mathrm{q} 33$ is linked to, and associated with, type 1 diabetes. Hum Mol Genet 1996;5:10751080.

43 Marron MP, Zeidler A, Raffel LJ, Eckenrode SE, Yang JJ, Hopkins DI, Garchon HJ, Jacob CO, Serrano-Rios M, Martinez Larrad MT, Park Y, Bach JF, Rotter JI, Yang MC, She JX: Genetic and physical mapping of a type 1 diabetes susceptibility gene (IDDM12) to a $100-\mathrm{kb}$ phagemid artificial chromosome clone containing D2S72-CTLA4-D2S105 on chromosome 2q33. Diabetes 2000;49:492499.

44 Ueda H, Howson JM, Esposito L, Heward J, Snook H, Chamberlain G, Rainbow DB, Hunter KM, Smith AN, DiGenova G, Herr MH, Dahlman I, Payne F, Smyth D, Lowe C, Twells RC, Howlett S, Healy B, Nutland S, Rance HE, Everett V, Smink LJ, Lam AC, Cordell HJ, Walker NM, Bordin C, Hulme J, Motzo C, Cucca F, Hess JF, Metzker ML, Rogers J, Gregory S, Allahabadia A, Nithiyananthan R, Tuomilehto-Wolf E, Tuomilehto J, Bingley P, Gillespie KM, Undlien DE, Ronningen KS, Guja C, Ionescu-Tirgoviste C, Savage DA, Maxwell AP, Carson DJ, Patterson CC, Franklyn JA, Clayton DG, Peterson LB, Wicker LS, Todd JA, Gough SC: Association of the T-cell regulatory gene CTLA4 with susceptibility to autoimmune disease. Nature 2003;423:506511.

45 Anjos S, Nguyen A, Ounissi-Benkalha H, Tessier MC, Polychronakos C: A common autoimmunity predisposing signal peptide variant of the cytotoxic T-lymphocyte antigen 4 results in inefficient glycosylation of the susceptibility allele. J Biol Chem 2002;277:46478-46486.

46 Anjos SM, Tessier MC, Polychronakos C: Association of the cytotoxic T lymphocyte-associated antigen 4 gene with type 1 diabetes: evidence for independent effects of two polymorphisms on the same haplotype block. J Clin Endocrinol Metab 2004;89:6257-6265.
47 Anjos S, Polychronakos C: Mechanisms of genetic susceptibility to type I diabetes: beyond HLA. Mol Genet Metab 2004;81:187-195.

48 Anjos SM, Shao W, Marchand L, Polychronakos C: Allelic effects on gene regulation at the autoimmunity-predisposing CTLA4 locus: a re-evaluation of the $3^{\prime}+6230 \mathrm{G}>\mathrm{A}$ polymorphism. Genes Immun 2005;6:305-311.

49 Bottini N, Musumeci L, Alonso A, Rahmouni S, Nika K, Rostamkhani M, MacMurray J, Meloni GF, Lucarelli P, Pellecchia M, Eisenbarth GS, Comings D, Mustelin T: A functional variant of lymphoid tyrosine phosphatase is associated with type 1 diabetes. Nat Genet 2004; 36:337-338

$50 \mathrm{Qu}$ H, Tessier MC, Hudson TJ, Polychronakos $\mathrm{C}$ : Confirmation of the association of the R620W polymorphism in the protein tyrosine phosphatase PTPN22 with type 1 diabetes in a family based study. J Med Genet 2005;42: 266-270.

51 Smyth D, Cooper JD, Collins JE, Heward JM, Franklyn JA, Howson JM, Vella A, Nutland S, Rance HE, Maier L, Barratt BJ, Guja C, Ionescu-Tirgoviste C, Savage DA, Dunger DB, Widmer B, Strachan DP, Ring SM, Walker N, Clayton DG, Twells RC, Gough SC, Todd JA: Replication of an association between the lymphoid tyrosine phosphatase locus (LYP/ PTPN22) with type 1 diabetes, and evidence for its role as a general autoimmunity locus. Diabetes 2004;53:3020-3023.

52 Onengut-Gumuscu S, Ewens KG, Spielman RS, Concannon P: A functional polymorphism $(1858 \mathrm{C} / \mathrm{T})$ in the PTPN22 gene is linked and associated with type I diabetes in multiplex families. Genes Immun 2004;5:678-680.

53 Ladner MB, Bottini N, Valdes AM, Noble JA: Association of the single nucleotide polymorphism C1858T of the PTPN22 gene with type 1 diabetes. Hum Immunol 2005;66:60-64.

54 Hill RJ, Zozulya S, Lu YL, et al: The lymphoid protein tyrosine phosphatase Lyp interacts with the adaptor molecule Grb2 and functions as a negative regulator of T-cell activation. Exp Hematol 2002;30:237-244.

55 Cohen S, Dadi H, Shaoul E, et al: Cloning and characterization of a lymphoid-specific inducible human protein tyrosine phosphatase, Lyp. Blood 1999;93:2013.

56 Hasegawa K, Martin F, Huang G, Tumas D, Diehl L, Chan AC: PEST domain-enriched tyrosine phosphatase (PEP) regulation of effector/memory T cells. Science 2004; $303: 685-$ 689.

$>57$ Cloutier JF, Veillette A: Cooperative inhibition of $\mathrm{T}$-cell antigen receptor signaling by a complex between a kinase and a phosphatase. J Exp Med 1999;189:111-121.

58 Polychronakos C: Animal models of spontaneous autoimmune diabetes: notes on their relevance to the human disease. Curr Diab Rep 2004; 4:151-154.

59 Polychronakos C: Impact of the Human Genome Project on pediatric endocrinology. Horm Res 2003;59:55-65. 